\title{
An Approach to Evaluating Computer Network Security with Intuitionistic Trapezoidal Fuzzy Information
}

\author{
Ming Xue \\ Henan University of Technology, Zhengzhou, Henan 450001, China \\ Correspondence should be addressed to Ming Xue; xueming11980@163.com
}

Received 29 June 2014; Accepted 9 July 2014; Published 17 July 2014

Academic Editor: Xiaofei Zhao

Copyright (C) 2014 Ming Xue. This is an open access article distributed under the Creative Commons Attribution License, which permits unrestricted use, distribution, and reproduction in any medium, provided the original work is properly cited.

\begin{abstract}
We investigate the multiple attribute decision-making problems for evaluating the computer network security with intuitionistic trapezoidal fuzzy information. We utilize the intuitionistic trapezoidal fuzzy weighted average (ITFWA) operator to aggregate the intuitionistic trapezoidal fuzzy information corresponding to each alternative and get the overall value of the alternatives and then rank the alternatives and select the most desirable one(s) according to the distance between the overall value of the alternatives and ideal solution. Finally, an illustrative example for evaluating the computer network security is given.
\end{abstract}

\section{Introduction}

With science and technology development, computer technology improves constantly and more and more software and hardware of education industry have appeared [1]. Uses in educating the profession especially the software and the hardware appear one after another, have brought a lot of convenience for the school teaching management, and simultaneously have also provided many convenient conditions for teacher's and student's daily life. The application of these hightechs in the school convenient for the educational circles also gave the educational circles a question about the safety of the information management; the network security question has become a new question to educational circles [2,3]. As a result of a one-card appearance, the school has applied this technology in the first time. It provides the convenience for both teachers and students. Meanwhile, the school also must consider the safety of the card. The enhancement of network and the server security is the most important thing for schools. These high-techs, for example, multimedia slides, network information, laser projection, and so on, bring about new breakthrough to school education. The emergence of one-card also as the education sector development has played a role and significantly improved the management of schools in various fields [4]. The appearance of the card has solved a lot of niggling problems and makes the campus consumptions more convenient. A card can be slippery in school, and it also facilitates schools in wealth management. The development of the education sector is affected by the technical implications and also constrained by economic conditions, particularly those three-table institutions or nongovernmental institutions. They strive to build a modern campus and, therefore, will not abandon advanced technology to serve schools. However, due to shortage of funds, schools are often just going to the application but did not consider the quality and future problems. In the tender, as long as the low price of whom, let someone to do the construction, this is wrong. For modern campus, improving the technology is right, but it is also needed to consider the question of safety and quality, especially one-card; security is a particularly important problem which cannot be ignored. The author participated in a one-card case of a university and is responsible for the construction of a hardware and server tender selection and purchasing also the maintenance work later. But due to the problem of school funds, this makes some very good companies unsuccessful and the midrange be elected. The author also went to a survey of many institutions and made a research about the operation of the campus card and the cooperations of those universities. All the institutions the author picked are capable; they only consider the quality not the price. To make the card more secure for our school, the author got the school's secret instructions and carried 
out mock attacks in order to detect the one-card server background security issues. Although we spent less money, to require security comes first. Only school leadership and the direct leadership know about this action. Since those IP and screen shots in the papers are not real, they are very similar. This task is to be possible to control all of the servers, so we can require developers to do the upgrade or debugging, guarantee the safety of the school network server, and make future work be well prepared [5]. This school contains campus network, one-card service, postal savings, and other financial systems. All of these four systems are in one network, so the security is the most important thing. The information on the network is real money; if any problem occurs, the consequence will be unable to be estimated. With the fast development of Internet technologies recently, computer networks have played an increasingly important role in the fields of politics, economy, military, and social life. Although network technologies bring about endless convenience for people's life and work, the openness and interconnection of networks make network attacks become more universal, and network security problems have attracted wide attention. Risk always exists in the real network environment. In order to ensure normal operation of networks, hidden troubles in networks must be identified and analyzed, and proper measures must be adopted to decrease the risk according to analysis results. Therefore, how to accurately evaluate the security of a network becomes an important problem, and it has been one of the research focuses in the field of network security [6].

Hao and Li [7] proposed a new sorting method which used the possible degree matrix to solve the sorting problem of intuitionistic trapezoidal fuzzy numbers. Wang [8] reviewed the current research on the multicriteria linguistic decision-making methods and fuzzy multicriteria decisionmaking methods based on fuzzy number, intuitionistic fuzzy set, and vague set and then proposed the definition of intuitionistic trapezoidal fuzzy numbers and interval intuitionistic trapezoidal fuzzy number. Wang and Zhang [9] proposed a multicriteria decision-making approach for multicriteria decision-making problems in which weight information was not completely known and the criteria values were intuitionistic trapezoidal fuzzy numbers. Wan and Dong [10] studied the multiattribute group decision-making method based on intuitionistic trapezoidal fuzzy numbers. Firstly, the expectations and the expected score of intuitionistic trapezoidal fuzzy number were defined based on the function of the gravity center of the image. Secondly the IT-OWA and ITHA operators were proposed. Based on these operators, the multiattribute group decision-making method based on intuitionistic trapezoidal fuzzy number was presented. Wang et al. [11] proposed the intuitionistic trapezoidal fuzzy geometric aggregation operators, including the intuitionistic trapezoidal fuzzy weighted geometric (IT-WG) operator, intuitionistic trapezoidal fuzzy ordered weighted geometric (IT-OWG) operator, and intuitionistictrapezoidal fuzzy hybrid geometric (IT-HG) operator. Then the multicriteria decisionmaking method based on the aggregation operators was proposed. Wu and Liu [12] proposed the interval-valued intuitionistic trapezoidal fuzzy weighted geometric (IVITFWG) operator, the interval-valued intuitionistic trapezoidal fuzzy ordered weighted geometric (IVITFOWG) operator, and the interval-valued intuitionistic trapezoidal fuzzy hybrid geometric (IVITFHG) operator. Wu and Cao [13] and Wei et al. [14] proposed the interval intuitionistic trapezoidal fuzzy weighted geometric (IITFWG) operator, the interval intuitionistic trapezoidal fuzzy ordered weighted geometric (IITFOWG) operator, and interval intuitionistic trapezoidal fuzzy hybrid geometric (IITFHG) operator, and based on these operators, a new decision-making method was presented to solve the MAGDM problems in which attribute values take the form of interval intuitionistic trapezoidal fuzzy numbers.

In this paper, we investigate the multiple attribute decision-making problems for evaluating the computer network security with intuitionistic trapezoidal fuzzy information. We utilize the intuitionistic trapezoidal fuzzy weighted average (ITFWA) operator to aggregate the intuitionistic trapezoidal fuzzy information corresponding to each alternative and get the overall value of the alternatives and then rank the alternatives and select the most desirable one(s) according to the distance between the overall value of the alternatives and ideal solution. Finally, an illustrative example for evaluating the computer network security is given.

\section{Preliminaries}

In the following, we will introduce some basic concepts related to intuitionistic trapezoidal fuzzy numbers.

Definition 1. Let $\tilde{a}$ be an intuitionistic trapezoidal fuzzy number; its membership function is $[9,15]$

$$
\mu_{\tilde{a}}(x)= \begin{cases}\frac{x-a}{b-a} \mu_{\tilde{a}}, & a \leq x<b \\ \mu_{\widetilde{a}}, & b \leq x \leq c \\ \frac{d-x}{d-c} \mu_{\widetilde{a}}, & c<x \leq d \\ 0, & \text { others. }\end{cases}
$$

Its nonmembership function is

$$
\nu_{\widetilde{a}}(x)= \begin{cases}\frac{b-x+\nu_{\tilde{a}}\left(x-a_{1}\right)}{b-a_{1}}, & a_{1} \leq x<b ; \\ \frac{\nu_{\widetilde{a}},}{x-c+\nu_{\widetilde{a}}\left(d_{1}-x\right)} & b \leq x \leq c ; \\ d_{1}-c & c<x \leq d_{1} \\ 0, & \text { others }\end{cases}
$$

where $0 \leq \mu_{\widetilde{a}} \leq 1 ; 0 \leq \nu_{\widetilde{a}} \leq 1$; and $\mu_{\widetilde{a}}+\nu_{\widetilde{a}} \leq 1 ; a, b, c$, $d \in R$

In the following, Wei developed a new operator called intuitionistic trapezoidal fuzzy weighted average (ITFWA) operator [16].

Definition 2 (see [16]). Let $\tilde{a}_{j}=\left(\left[a_{j}, b_{j}, c_{j}, d_{j}\right] ; \mu_{\widetilde{a}_{j}}\right.$, $\left.\nu_{\tilde{a}_{j}}\right)(j=1,2, \ldots, n)$ be a collection of intuitionistic 
trapezoidalfuzzy numbers, and let ITFWA: $Q^{n} \rightarrow Q$, if

$$
\begin{aligned}
& \operatorname{ITFWA}_{\omega}\left(\widetilde{a}_{1}, \widetilde{a}_{2}, \cdots, \widetilde{a}_{n}\right) \\
& =\bigoplus_{j=1}^{n}\left(\omega_{j} \otimes \widetilde{a}_{j}\right) \\
& =\left(\left[\sum_{j=1}^{n} \omega_{j} a_{j}, \sum_{j=1}^{n} \omega_{j} b_{j}, \sum_{j=1}^{n} \omega_{j} c_{j}, \sum_{j=1}^{n} \omega_{j} d_{j}\right] ;\right. \\
& \left.\quad 1-\prod_{j=1}^{n}\left(1-\mu_{\tilde{a}_{j}}\right)^{\omega_{j}}, \prod_{j=1}^{n}\left(\nu_{\tilde{a}_{j}}\right)^{\omega_{j}}\right),
\end{aligned}
$$

where $\omega=\left(\omega_{1}, \omega_{2}, \ldots, \omega_{n}\right)^{T}$ is the weight vector of $\widetilde{a}_{j}(j=$ $1,2, \ldots, n)$ and $\omega_{j} \geq 0, \sum_{j=1}^{n} \omega_{j}=1$; then ITFWA is called the intuitionistic trapezoidal fuzzy weighted average (ITFWA) operator.

Definition 3 (see [16]). For a normalized intuitionistic trapezoidal fuzzy decision-making matrix $\widetilde{R}=\left(\widetilde{r}_{i j}\right)_{m \times n}=$ $\left(\left[a_{i j}, b_{i j}, c_{i j}, d_{i j}\right] ; \mu_{i j}, v_{i j}\right)_{m \times n}$, where $0 \leq a_{i j} \leq b_{i j} \leq c_{i j} \leq d_{i j} \leq 1$, $0 \leq \mu_{i j}, v_{i j} \leq 1,0 \leq \mu_{i j}+v_{i j} \leq 1$, the intuitionistic trapezoidal fuzzy positive ideal solution is defined as follows:

$$
\widetilde{r}^{+}=\left(\left[a^{+}, b^{+}, c^{+}, d^{+}\right] ; \mu^{+}, v^{+}\right)=([1,1,1,1] ; 1,0) .
$$

Definition 4 (see [16]). Let $\widetilde{a}_{1}=\left(\left[a_{1}, b_{1}, c_{1}, d_{1}\right] ; \mu_{\widetilde{a}_{1}}, v_{\widetilde{a}_{1}}\right)$ and $\widetilde{a}_{2}=\left(\left[a_{2}, b_{2}, c_{2}, d_{2}\right] ; \mu_{\tilde{a}_{2}}, v_{\tilde{a}_{2}}\right)$ be two intuitionistic trapezoidal fuzzy numbers; then the normalized Hamming distance between $\widetilde{a}_{1}$ and $\widetilde{a}_{2}$ is defined as follows:

$$
\begin{aligned}
d\left(\widetilde{a}_{1}, \widetilde{a}_{2}\right)=\frac{1}{8}( & \left|\left(1+\mu_{\widetilde{a}_{1}}-v_{\widetilde{a}_{1}}\right) a_{1}-\left(1+\mu_{\widetilde{a}_{2}}-v_{\widetilde{a}_{2}}\right) a_{2}\right| \\
& +\left|\left(1+\mu_{\widetilde{a}_{1}}-v_{\widetilde{a}_{1}}\right) b_{1}-\left(1+\mu_{\widetilde{a}_{2}}-v_{\widetilde{a}_{2}}\right) b_{2}\right|
\end{aligned}
$$

$\widetilde{R}$

$$
=\left[\begin{array}{cccc}
([0.5,0.6,0.7,0.8] ; 0.5,0.4) & ([0.1,0.2,0.3,0.4] ; 0.6,0.3) & ([0.5,0.6,0.8,0.9] ; 0.3,0.6) & ([0.4,0.5,0.6,0.7] ; 0.2,0.7) \\
([0.6,0.7,0.8,0.9] ; 0.7,0.3) & ([0.5,0.6,0.7,0.8] ; 0.7,0.2) & ([0.4,0.5,0.7,0.8] ; 0.7,0.2) & ([0.5,0.6,0.7,0.9] ; 0.4,0.5) \\
([0.1,0.2,0.4,0.5] ; 0.6,0.4) & ([0.2,0.3,0.5,0.6] ; 0.5,0.4) & ([0.5,0.6,0.7,0.8] ; 0.5,0.3) & ([0.3,0.5,0.7,0.9] ; 0.2,0.3) \\
([0.3,0.4,0.5,0.6] ; 0.8,0.1) & ([0.1,0.3,0.4,0.5] ; 0.6,0.3) & ([0.1,0.3,0.5,0.7] ; 0.3,0.4) & ([0.6,0.7,0.8,0.9] ; 0.2,0.6) \\
([0.2,0.3,0.4,0.5] ; 0.6,0.2) & ([0.3,0.4,0.5,0.6] ; 0.4,0.3) & ([0.2,0.3,0.4,0.5] ; 0.7,0.1) & ([0.5,0.6,0.7,0.8] ; 0.1,0.3)
\end{array}\right] .
$$

Then, we utilize the approach developed to get the most desirable computer network system(s).

Step 1. Utilize the weight vector $\omega=(0.3,0.2,0.1,0.4)^{T}$, and by (3), we obtain the overall values $\widetilde{r}_{i}$ of the computer network systems $A_{i}(i=1,2,3,4,5)$ :

$$
\begin{aligned}
& \widetilde{r}_{1}=([0.37,0.46,0.65,0.71] ; 0.2435,0.6127), \\
& \widetilde{r}_{2}=([0.46,0.52,0.66,0.84] ; 0.4780,0.4011),
\end{aligned}
$$

$$
\begin{aligned}
& +\left|\left(1+\mu_{\tilde{a}_{1}}-v_{\widetilde{a}_{1}}\right) c_{1}-\left(1+\mu_{\widetilde{a}_{2}}-v_{\widetilde{a}_{2}}\right) c_{2}\right| \\
& \left.+\left|\left(1+\mu_{\widetilde{a}_{1}}-v_{\widetilde{a}_{1}}\right) d_{1}-\left(1+\mu_{\widetilde{a}_{2}}-v_{\widetilde{a}_{2}}\right) d_{2}\right|\right) .
\end{aligned}
$$

\section{Numerical Example}

With the popularization of computer technology, network provides great impetus for the advancement of society. However, the development of the network technology faces great challenges under the unceasing rigorous network situation, and traditional single-point heterogeneous security defense technologies, such as IDS, Firewall, and VPN, can enhance security performance of network system to a certain degree, among which lack of effective collaboration leads to being unable to monitor the whole network security situation. Under this circumstance, the research about network security situation awareness (NSSA) has upper academic value and comprehensive practical value. But the researches related to NSSA are still far away from maturation at the present. Most of the situation awareness models are based on single-source environment; quantification awareness methods mainly depend on quantifying the raw alerts of the security sensor and they cannot actualize the awareness of attack steps and sequences. The research about situation evaluation mainly focuses on the construction of index system and is lack of deep study in evaluation model and method. This section presents a numerical example to evaluate the computer network security with uncertain linguistic information to illustrate the method proposed in this paper. There are five possible computer network systems $A_{i}(i=$ $1,2,3,4,5)$ for four attributes $G_{j}(j=1,2,3,4)$. The four attributes include the tactics $\left(G_{1}\right)$, technology and economy $\left(G_{2}\right)$, logistics $\left(G_{3}\right)$, and strategy $\left(G_{4}\right)$, respectively. The five possible computer network systems $A_{i}(i=1,2, \ldots, 5)$ are to be evaluated using the intuitionistic trapezoidal fuzzy information by the decision maker under the above four attributes whose weighting vector $\omega=(0.3,0.2,0.1,0.4)^{T}$, as listed in the following matrix

$$
\begin{aligned}
& \widetilde{r}_{3}=([0.30,0.43,0.61,0.72] ; 0.4203,0.4521), \\
& \widetilde{r}_{4}=([0.22,0.43,0.51,0.67] ; 0.3055,0.4322), \\
& \widetilde{r}_{5}=([0.23,0.35,0.42,0.51] ; 0.4954,0.3247) .
\end{aligned}
$$

Step 2. Calculate the distances between overall values $\widetilde{r}_{i}=$ $\left(\left[a_{i}, b_{i}, c_{i}, d_{i}\right] ; \mu_{i}, v_{i}\right)$ and intuitionistic trapezoidal fuzzy 
positive ideal solution $\widetilde{r}^{+}=\left(\left[a^{+}, b^{+}, c^{+}, d^{+}\right] ; \mu^{+}, v^{+}\right)=([1,1$, $1,1] ; 1,0)$ :

$$
\begin{gathered}
d\left(\widetilde{r}_{1}, \widetilde{r}^{+}\right)=0.8435, \quad d\left(\widetilde{r}_{2}, \widetilde{r}^{+}\right)=0.6568, \\
d\left(\widetilde{r}_{3}, \widetilde{r}^{+}\right)=0.7089, \quad d\left(\widetilde{r}_{4}, \widetilde{r}^{+}\right)=0.7879, \\
d\left(\widetilde{r}_{5}, \widetilde{r}^{+}\right)=0.7326 .
\end{gathered}
$$

Step 3. Rank all the alternatives $A_{i}(i=1,2,3,4,5)$ in accordance with the distances $d\left(\widetilde{r}_{i}, \widetilde{r}^{+}\right)$between overall values $\widetilde{r}_{i}=\left(\left[a_{i}, b_{i}, c_{i}, d_{i}\right] ; \mu_{i}, v_{i}\right)$ and intuitionistic trapezoidal fuzzy positive ideal solution: $A_{2}>A_{3}>A_{5}>A_{4}>A_{1}$, and thus the most desirable computer network system is $A_{2}$.

\section{Conclusion}

Computer network security assessment is an active security technology, which can make network information system more secure and robust. Taking so many security factors such as threats, assets, and vulnerabilities into account, the computer network security assessment technology can help administrators take an active attitude to identify those potential threats that their systems will be exposed to. Now it has become the fundamental work and the key link for the national information assurance framework. When we rely more and more on the world of Internet day by day, research on network information risk assessment will be one of the research focuses in the network security field. The research of this dissertation focuses on the quantitative methodologies of the network security assessment. In this paper, we investigate the multiple attribute decision-making problems for evaluating the computer network security with intuitionistic trapezoidal fuzzy information. We utilize the intuitionistic trapezoidal fuzzy weighted average (ITFWA) operator to aggregate the intuitionistic trapezoidal fuzzy information corresponding to each alternative and get the overall value of the alternatives and then rank the alternatives and select the most desirable one(s) according to the distance between the overall value of the alternatives and ideal solution. Finally, an illustrative example for evaluating the computer network security is given.

\section{Conflict of Interests}

The author declares that there is no conflict of interests regarding the publication of this paper.

\section{References}

[1] X. Mo, "Research on the computer network security evaluation based on the ULCGM operator with uncertain linguistic information," Journal of Convergence Information Technology, vol. 8, no. 3, pp. 160-166, 2013.

[2] G. Zhang, H. Li, R. Chen et al., "Research and design on vulnerability testing in computer network security system," Advances in Information Sciences and Service Sciences, vol. 5, no. 7, pp. 1-10, 2013.

[3] G. Song, "Computer network security and precaution evaluation based on incremental relevance vector machine algorithm and ACO," International Journal on Advances in Information Sciences and Service Sciences, vol. 5, no. 1, pp. 120-127, 2013.

[4] Y. Li, J. Yin, and G. Wu, "Model for evaluating the computer network security with interval-valued intuitionistic fuzzy information," International Journal of Digital Content Technology and Its Applications, vol. 6, no. 6, pp. 140-146, 2012.

[5] J. Dong, "An approach to evaluating the computer network security with hesitant fuzzy information," International Journal of Digital Content Technology and Its Applications, vol. 6, no. 20, pp. 633-639, 2012.

[6] Y. Li, X. Shan, and G. Wu, "Comprehensive evaluation model for computer network security with linguistic information," Advances in Information Sciences and Service Sciences, vol. 3, no. 9, pp. 126-131, 2011.

[7] F. L. Hao and D. Q. Li, "Anewranking method of fuzzy numbers," Journal of Ordnance Engineering College, vol. 19, pp. 73-75, 2007.

[8] J. Q. Wang, "Overview on fuzzy multi-criteria decision-making approach," Control and Decision, vol. 23, pp. 601-607, 2008.

[9] J. Q. Wang and Z. Zhang, "Multi-criteria decision-making method with incomplete certain information based on intuitionistic fuzzy numbers," Control and Decision, vol. 24, no. 2, pp. 226-230, 2009.

[10] S. P. Wan and J. Y. Dong, "Method of the intuitionistic trapezoidal fuzzy number for multi-attribute group decision," Control and Decision, vol. 25, no. 5, pp. 773-776, 2010.

[11] Y. Wang, S. F. Zhang, and S. Q. Xie, "Intuitionistic trapezoidal fuzzy geometric aggregation operators and their application to group decision making," Value Engineering, vol. 27, pp. 159-161, 2012.

[12] J. Wu and Y. Liu, "An approach for multiple attribute group decision making problems with interval-valued intuitionistic trapezoidal fuzzy numbers," Computers \& Industrial Engineering, vol. 66, pp. 311-324, 2013.

[13] J. Wu and Q. Cao, "Same families of geometric aggregation operators with intuitionistic trapezoidal fuzzy numbers," Applied Mathematical Modelling, vol. 37, no. 1-2, pp. 318-327, 2013.

[14] G. Wei, X. Zhao, and H. Wang, "An approach to multiple attribute group decision making with interval intuitionistic trapezoidal fuzzy information," Technological and Economic Development of Economy, vol. 18, no. 2, pp. 317-330, 2012.

[15] J. Wang and Z. Zhang, "Programming method of multi-criteria decision-making based on intuitionistic fuzzy number with incomplete certain information," Control and Decision, vol. 23, no. 10, p. 1145, 2008.

[16] G. Wei, "Some arithmetic aggregation operators with intuitionistic trapezoidal fuzzy numbers and their application to group decision making," Journal of Computers, vol. 5, no. 3, pp. 345351, 2010. 

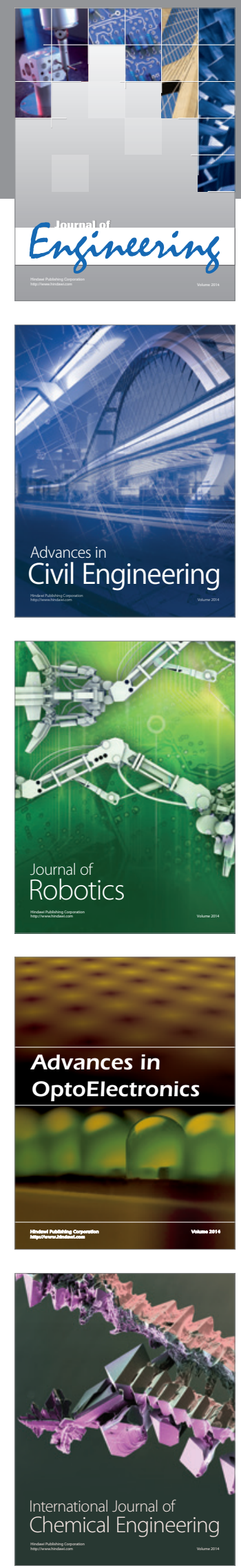

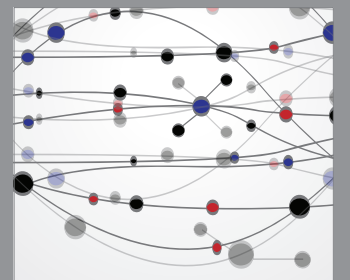

The Scientific World Journal
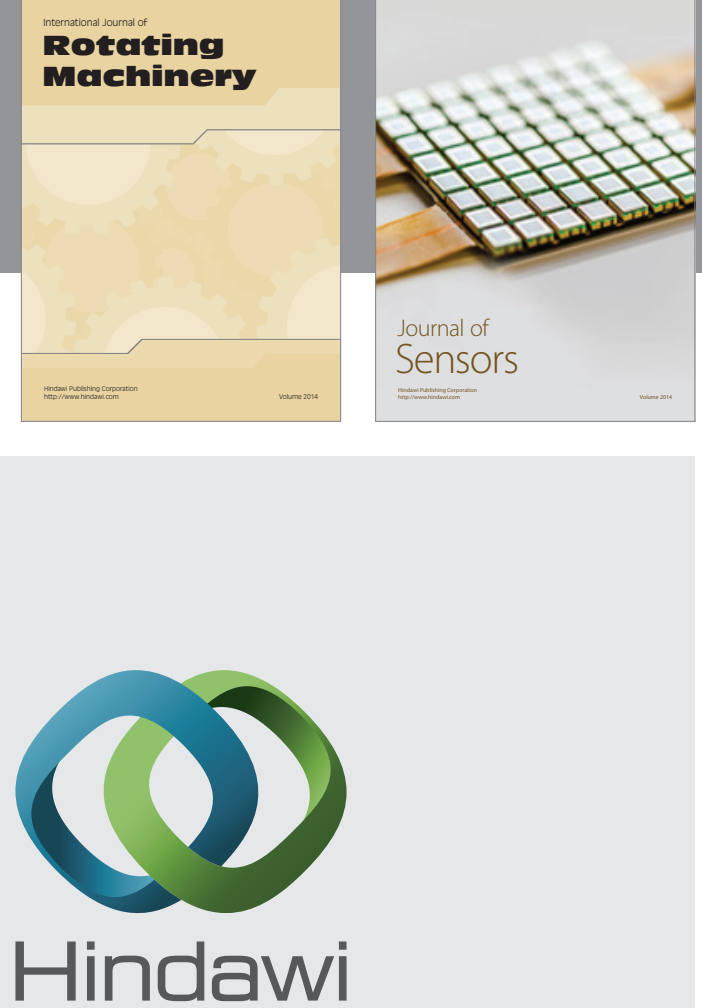

Submit your manuscripts at http://www.hindawi.com
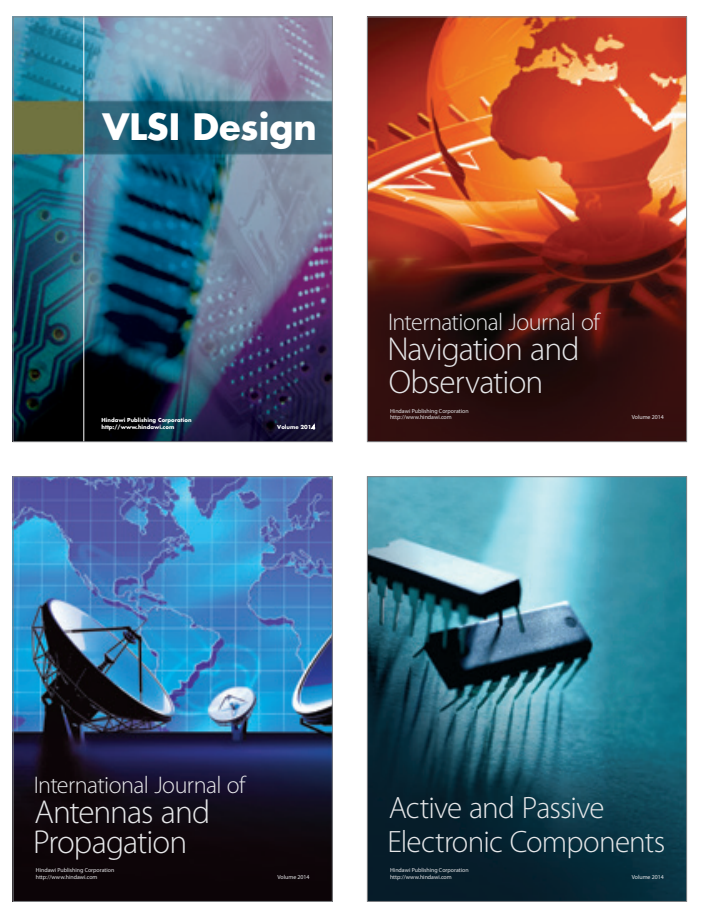
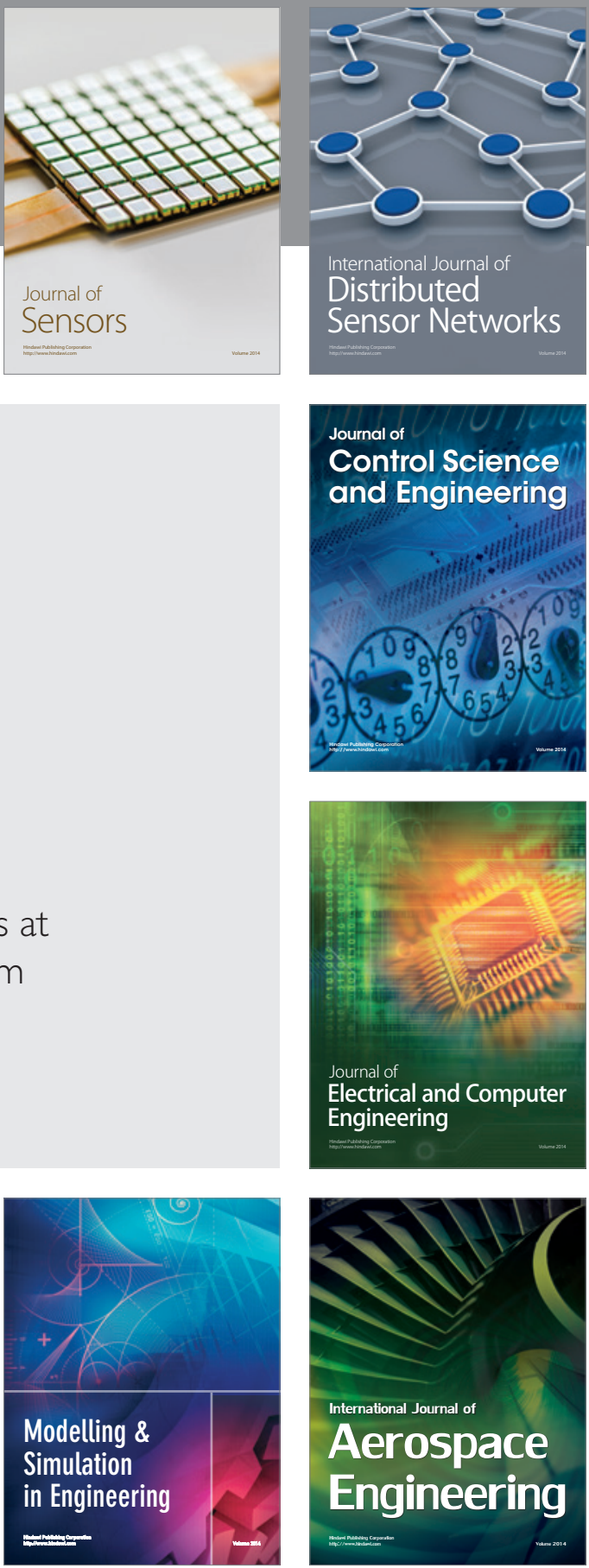

Journal of

Control Science

and Engineering
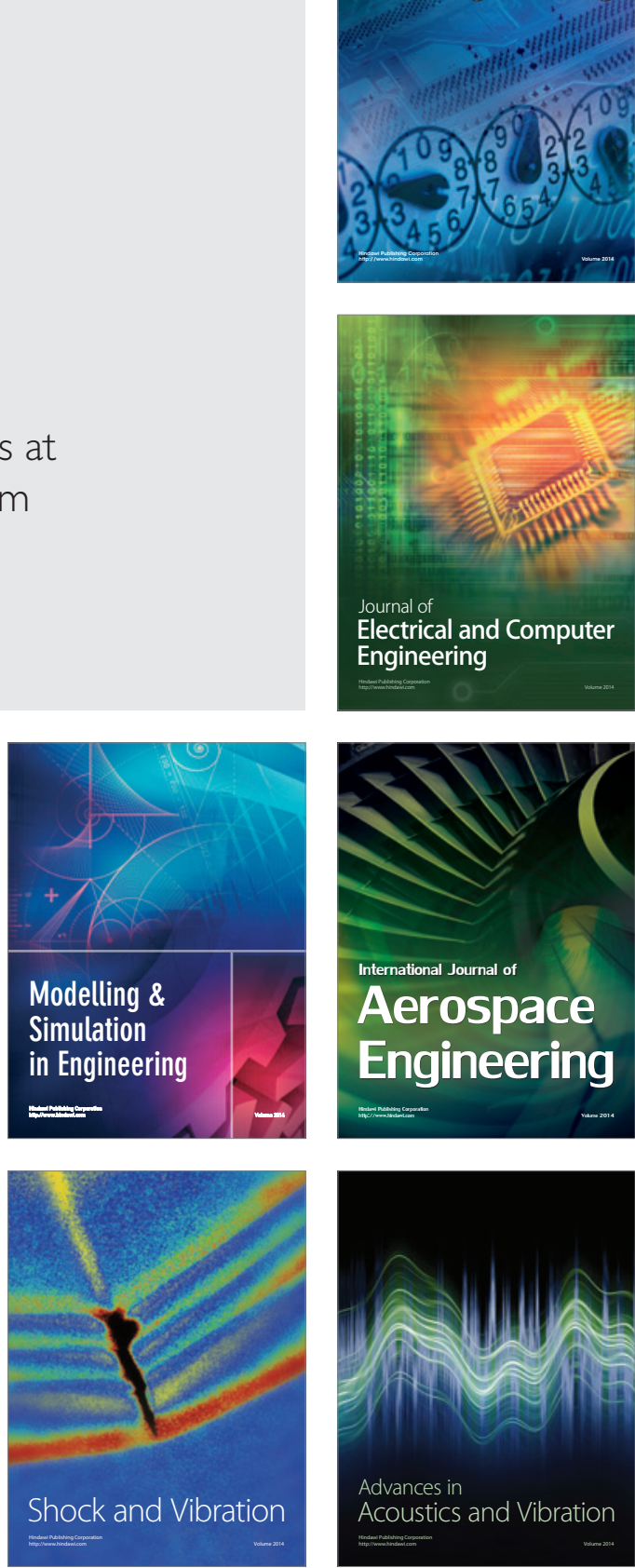